\title{
“TURISMO CONSCIENTE”, DESDE LA ÓPTICA DE LOS EXPERTOS
}

\author{
E. A. CASTILLO MONTESDEOCA ${ }^{1}$, M. E. VÁZQUEZ ROZAS ${ }^{2}$ e F. MARTÍNEZ-ROGET ${ }^{3}$ \\ Universidad de las Fuerzas Armadas ESPE ${ }^{1}$, Universidad de Santiago de Compostela ${ }^{2,3}$ \\ eacastillo@espe.edu.ec ${ }^{1}$
}

Submetido 18/01/2017 - aceptado 28/03/2020

DOI: $10.15628 /$ holos.2020.5565

\section{RESUMEN}

El "Turismo Consciente" es una propuesta ecuatoriana que se origina en junio 2011 en el marco de la Conferencia Iberoamericana de Ministros de Turismo, en donde se presenta por primera vez esta iniciativa; seguida del II Congreso Internacional de Ética y Turismo de la OMT, septiembre 2012, donde se lanza por Ecuador su definición, que encaja perfectamente con el Código de Ética Mundial de Turismo de la OMT. "Una experiencia de vida transformadora que genera un crecimiento personal que nos convierte en mejores seres humanos. Este nuevo concepto se sustenta en los principios de sostenibilidad y ética y promueve los volcanes de la paz, la amistad, el respeto y amor a la vida como esencia de la práctica turística." El "Turismo Consciente" incluye el turismo responsable socialmente, el sostenible, el medio ambiente y el ético. En este trabajo se utiliza la triangulación de datos y metodológica para establecer el alcance de esta nueva iniciativa, la identificación de los factores y variables que lo constituyen, desde el punto de vista de los expertos del turismo.

Los principales resultados permiten conceptualizar al "Turismo Consciente" como una filosofía, que es una evolución del turismo sostenible, orientado en grupos de interés como son los seres humanos, las comunidades locales anfitrionas, las empresas y las instituciones públicas.

PALABRAS-CLAVE: Turismo Consciente, ética, sostenible, modalidades del turismo, Ecuador.

\section{"CONSCIOUS TOURISM" FROM THE PERSPECTIVE OF EXPERTS}

\begin{abstract}
"Conscious Tourism" is an Ecuadorian proposal that originates in June 2011 in the framework of the IberoAmerican Conference of Ministers of Tourism, where first introduced this initiative; followed by the Second International Congress on Ethics and Tourism of the World Tourism Organization, in September 2012, which is released by Ecuador definition, which fits perfectly with the Global Code of Ethics for Tourism of the WTO. "A life transforming experience that generates personal growth that makes us better human beings. This new concept is based on the principles of sustainability and ethics and promotes the volcanoes of peace, friendship, respect and
\end{abstract}

love of life as the essence of tourism practice. "Conscious Tourism" includes tourism socially responsible, the sustainable, environment and ethical.

In this paper we use data and methodological triangulation to establish the scope of this new initiative, the identification of the factors and variables that constitute it, from the point of view of tourism experts. The main results allow us to conceptualize "Conscious Tourism" as a philosophy, which is an evolution of sustainable tourism, oriented to interest groups such as human beings, local host communities, companies and public institutions.

KEYWORDS: Conscious Tourism, ethical, sustainable, forms of tourism, Ecuador. 


\section{INTRODUCCIÓN}

El "Turismo Consciente" tiene su origen en la iniciativa ecuatoriana que comparte los principios del turismo alternativo, accesible, sostenible y social; que se contrapone al turismo de masas, de sol y playa. El modelo turístico de masas presenta una serie de problemas estructurales como la estacionalidad y la concentración espacial, producto de su adaptación a la situación socioeconómica y a una demanda cambiante (Ávila \& Barrado, 2005).

En el marco de la XI Conferencia Iberoamericana de Ministros de Turismo, en Asunción Paraguay, en mayo del 2011, se presentó por primera vez el "Turismo Consciente". Dicha propuesta fue respaldada por unanimidad e incluida en la Declaración Conjunta firmada por ministros y autoridades de turismo de 23 países de Iberoamérica y el Secretario General de la Organización Mundial de Turismo, Sr. Rifai Taleb (Red de la Organización Mundial de Turismo, 2011).

En el II Congreso Internacional de Ética y Turismo de la OMT, septiembre 2012, se puso de relieve que los grupos de interés del "Turismo Consciente" son los seres humanos, las comunidades locales y las actividades empresariales (Organización Mundial del Turismo, 2013a).

El II Congreso Internacional de Ética y Turismo concluye que el "Turismo Consciente" representa una forma de pensamiento innovador, basada en los principios de sostenibilidad y ética que promueven los valores de la paz, la amistad, el respeto y el amor a la vida como esencia de la práctica del turismo.

En relación a los seres humanos, su fin es que vean en los viajes una experiencia vital transformadora, capaz de inducir al crecimiento personal y enriquecimiento, que se transforme en una celebración de la vida y en una búsqueda de la felicidad. La aplicación en la práctica de este concepto contribuye a elevar el "índice del buen vivir"

El "Turismo Consciente" ofrece un pacto de convivencia entre las comunidades anfitrionas y los visitantes, entre el patrimonio cultural y natural, redefine los factores de consumo y mide la prosperidad más en términos espirituales que en bienes materiales, fomentando un crecimiento en beneficio de la sociedad.

La aplicación del "Turismo Consciente" en las actividades empresariales debe contribuir a mejorar la competitividad en una sociedad comprometida y alerta, con beneficios económicos y que contribuyan socialmente (Organización Mundial del Turismo, 2013b).

En el marco de Economía, la Feria Internacional de Turismo, FITUR 2012, el Ministerio de Turismo del Ecuador y la Organización Mundial de Turismo, OMT, apuestan por el "Turismo Consciente". "Su filosofía se basa en la consciencia humana, en el buen vivir, en dar y recibir; el turismo nos convierte en mejores personas" (Europa Press, 2012).

Un aspecto relevante es el Plan del Buen Vivir 2013 - 2017, en el cual se establecen cuatro ejes interactuantes y complementarios para lograr los objetivos en el largo plazo del Ecuador. Siendo uno de estos ejes la "Matriz productiva y los ejes estratégicos", en donde se prevé que Ecuador para el 2030, exportará un 40\% de servicios de alto valor agregado y con una participación relevante del turismo. En este contexto, uno de los objetivos nacionales para el Buen Vivir es: 
"Impulsar la transformación de la matriz productiva", siendo el turismo considerado un sector prioritario para la atracción de inversión nacional y extranjera; y en donde se busca posicionar el "Turismo Consciente" como un concepto de vanguardia a nivel nacional e internacional, con la participación del estado, el sector privado y popular; entregando un turismo ético, responsable, sostenible e incluyente (Secretaría Nacional de Planificación y Desarrollo Ecuador, 2013).

Ecuador promueve el "Turismo Consciente", como una propuesta diferenciadora que le permita beneficiarse de los Mundos de Ecuador: "Galápagos, Costa, Sierra y Amazonía", con una oferta turística centrada en distintos productos, desplegados en el Plan Estratégico de Turismo Ecuador 2020, PLANDETUR2020, que se enfoca en 11 líneas de turismo: Circuitos Generales, Sol y Playa, Turismo Comunitario, Turismo Cultural, Parques Temáticos, Ecoturismo y Turismo de Naturaleza, Turismo de Deportes y Aventura, Turismo de Salud, Agroturismo, Turismo de Convenciones y Congresos y Turismo de Cruceros (Ministerio de Turismo del Ecuador, 2007).

El "Turismo Consciente" es "Amar la vida" y una primera definición es: "Una experiencia de vida transformadora que genera un crecimiento personal que nos convierte en mejores seres humanos. Este nuevo concepto se sustenta en los principios de sostenibilidad y ética y promueve los volcanes de la paz, la amistad, el respeto y amor a la vida como esencia de la práctica turística. Constituye un pacto de convivencia, responsabilidad, respeto mutuo y comunión entre los agentes turísticos de las comunidades emisoras y receptoras, el turista y el patrimonio natural y cultural. El "Turismo Consciente" es un concepto vivo, dinámico y en constante construcción. Es una experiencia de dar y recibir." (Organización Mundial del Turismo, 2011).

A pesar de que aparecen mencionadas algunas características en relación con el "Turismo Consciente", no existe una definición clara y amplia, por lo menos no desde el punto de vista de la literatura científica, que aborde con precisión este concepto. El objetivo de este trabajo es precisamente el de arrojar mayor precisión en relación con el término, los grupos de interés y factores que enmarcan esta iniciativa. Es por ello que se ha buscado la participación de expertos en el turismo.

La investigación científica pretende encontrar respuesta a los problemas relevantes que el hombre se plantea y lograr hallazgos significativos que aumenten su acervo de conocimientos. Los resultados son consistentes y confiables mediante un proceso que implica la concatenación lógica de una serie de procesos específicos. Se apoya en teorías e hipótesis, y utiliza técnicas e instrumentos de recolección y análisis de datos con el propósito de conocer objetivamente las causas y las consecuencias o las modalidades que adoptan los fenómenos en determinado momento o durante el transcurso del tiempo (Rojas, 1991). En las ciencias sociales y en general, el tipo de problemática a tratar determina el tipo de investigación que debe aplicar. La literatura refiere dos tipos de investigación: la cuantitativa y la cualitativa.

La investigación cualitativa es un campo interdisciplinario, transdisciplinario y, a veces, contradisciplinario. Es multiparadigmática y enfocada sobre un objeto. Sus practicantes son sensibles al valor de la aproximación a través de muchos métodos. Se reúnen en torno a una perspectiva naturalista y un conocimiento interpretativo de la experiencia humana... La investigación cualitativa abraza dos tipos de tensiones al mismo tiempo: de una parte, está penetrada por una amplia sensibilidad interpretativa, postmoderna, feminista y crítica; de otra 
parte, está ligada más estrechamente a concepciones de la experiencia humana y su análisis en términos positivistas, pos positivistas, humanistas y naturalistas (Nelson et al., 1992).

La investigación cualitativa Consiste en una serie de prácticas materiales e interpretativas que hacen visible el mundo y lo transforman, lo convierten en una serie de representaciones que incluyen las notas de campo, las entrevistas, las conversaciones, las fotografías, las grabaciones y las notas para el investigador. Implica un enfoque interpretativo y naturalista del mundo, lo cual significa que los investigadores cualitativos estudian las cosas en sus escenarios naturales, tratando de entender o interpretar los fenómenos en función de los significados que las personas les dan (Denzin \& Lincoln, 2012).

El enfoque cualitativo presta mayor atención a lo profundo de los resultados y no a su generalización. En el enfoque cuantitativo lo importante es la generalización o universalización de los resultados. El enfoque cualitativo es un proceso circular y no siempre la secuencia es la misma, varía de acuerdo con cada estudio en particular. Tanto el proceso cualitativo como cuantitativo son considerados formas de hacer ciencia y producir conocimiento. El proceso general de la investigación puede resumirse en: planteamiento del problema, revisión de literatura, recolección de datos, análisis de los datos y reporte de resultados (Hernández et al., 2006a).

De la poca información existente al respecto, podría deducirse que el "Turismo Consciente", iría un poco más allá del turismo sostenible, incorporando posiblemente, además de los aspectos económicos, sociales y medioambientales, una cuarta dimensión relacionada con la preocupación por los aspectos éticos del turismo. Dicho planteamiento se sustenta en los siguientes cuestionamientos:

- El "Turismo Consciente", se sustenta en la sostenibilidad y la ética.

- ¿Podemos hablar de una cuarta dimensión, frente al turismo sostenible?

- Si el turismo sostenible considera las dimensiones de lo económico, social y medioambiental. ¿El "Turismo Consciente" podría diferenciarse por una cuarta dimensión? ¿Cuál es? ¿Cómo debería denominarse?

¿Qué aspectos o factores debe considerar esta cuarta dimensión?

El turismo impacta tanto positiva como negativamente en la economía, el medio ambiente, la cultura y la sociedad en general (Su et al. 2018; Almeida-García et al. 2016). Conceptos que se aproximan al planteamiento de la investigación del "Turismo Consciente", en tipologías como el turismo responsable que minimiza los impactos económicos, ambientales y sociales negativos; beneficia a la población local y contribuye a la conservación del patrimonio construido y ambiental (Goodwin, 2016), variables que forman parte de los grupos de interés del estudio. Lee y Col. (2017) destacaron la importancia percibida de los problemas éticos para el turismo responsable, que forman parte de la caracterización de la filosofía investigada.

Las tendencias del turismo buscan nuevas experiencias turísticas, que buscan atender una nueva demanda caracterizada por la independencia, el respeto y la responsabilidad hacia el medio ambiente y las comunidades anfitrionas. Los destinos turísticos y la ética están estrechamente vinculados, y como resultado, en la década de 1990, la Organización Mundial del Turismo (OMT) introdujo el Código Global de Ética para el Turismo (GCET), que proporciona un marco de referencia 
fundamental para el turismo responsable y sostenible (OMC, 2017), siendo parte del resultado del estudio, conforman la definición y caracterización del "Turismo Consciente".

\section{METOdOLOGÍA DE LA INVESTIGACIÓN}

El estudio cualitativo se enfoca y le interesa más las cualidades, por llegar a comprender e interpretar los sentidos sociales que los actores asignan a los distintos fenómenos, problemas, procesos, acciones.

El diseño de la investigación cualitativa implica tomar decisiones a lo largo de todo el proceso de investigación. "El diseño de un estudio naturalista por lo general no se establece completamente antes de que empiece el estudio, sino que emerge del tiempo que se recogen los datos, se lleva a cabo el análisis preliminar, y pasa a describirse de modo más completo en el contexto" (Erlandson et al., 1993, p. 66). El proceso tiene una secuencia lineal de pasos conceptuales, metodológicos y empíricos. Existe una interdependencia mutua de las partes individuales del proceso de investigación (Flick, 2012). El estudio cualitativo tiene como objetivo: la descripción de cualidades de un fenómeno; la búsqueda de un concepto que pueda abarcar una parte de la realidad; el descubrir tantas cualidades como sea posible; el entendimiento en profundidad. Para el estudio se utilizaron entrevistas por cuestionario electrónico, con preguntas cerradas principalmente, enfocados a profundizar sobre el concepto, los grupos de interés y los aspectos inherentes a cada grupo involucrado. Sumado a esto, se realizaron encuestas a profundidad, mediante una guía semiestructurada de preguntas abiertas relacionadas con los temas revisados en el cuestionario y que requería ser profundizados y discutidos con expertos interesados en el concepto.

\subsection{Identificación de los sujetos de estudio}

La identificación de los sujetos de estudio es necesario, con el fin de conocer las opiniones, sugerencias, comentarios y recomendaciones de expertos del sector turismo. El estudio abarcó los siguientes grupos de expertos del turismo:

- Expertos de Turismo, IV Congreso Internacional de Turismo, CIT 2015, Instituto Politécnico do Cávado e do Ave, Guimarães

- Expertos CETUR Galicia

- Expertos de Turismo del Sector Turismo de Ecuador

- Expertos de Turismo de las Universidades de España (Santiago de Compostela, Coruña, Vigo)

\subsection{Formulación de hipótesis}

La formulación de hipótesis consideró los siguientes supuestos:

- Existencia de un factor diferenciador (dimensión) del "Turismo Consciente

- La dimensión diferenciadora se denomina "Dimensión Ética"

- La dimensión que diferencia el Turismo Consciente es transversal 
- El principal factor que mide la dimensión diferenciadora en los seres humanos es una experiencia vital transformadora.

- El principal factor que mide la dimensión diferenciadora en las comunidades locales es un pacto de convivencia entre el patrimonio cultural y lo natural.

- El principal factor que mide la dimensión diferenciadora en las actividades empresariales es un compromiso con la sociedad.

\subsection{Métodos de recolección de datos}

Para la recolección de datos son necesarias técnicas de investigación para la recogida de datos, que describan los problemas y su significado. En este sentido Denzin (1992), señala que la triangulación no es una herramienta o estrategia de validación sino una alternativa a la validación; es la combinación de múltiples métodos, materiales empíricos, perspectivas y observadores focalizados en un estudio singular que debe ser entendida como una estrategia que agrega rigor, amplitud y profundidad a cualquier investigación. La estrategia de investigación se determina por la naturaleza de la cuestión a investigar. Cada estrategia cualitativa ofrece una perspectiva particular y única que orienta la realidad de una forma más fácil que otras. Algunas estrategias cualitativas se diseñan específicamente para un tipo de datos concretos, facilitando el control de ciertos tipos de observación. Los vínculos entre el tema de investigación y el método elegido determinan los resultados obtenidos y su utilidad (Denzin \& Lincoln, 1998).

Existen cuatro tipos de triangulación, entre los que se puede señalar: triangulación de datos que utiliza diversas fuentes de datos en el estudio; triangulación de investigadores que utiliza varios investigadores en el mismo estudio; triangulación de teorías que utiliza múltiples perspectivas teóricas para interpretar los datos y sus conclusiones; triangulación metodológica que utiliza diferentes métodos para estudiar el mismo problema (Denzin, 1978).

El estudio realizado utilizó una estrategia de triangulación de datos y métodos. En la triangulación de datos utilizando diferentes fuentes de datos, diferenciados por tiempo, espacio y personas. En la estrategia de datos hemos utilizado la documentación disponible (Acta de la XI Conferencia Iberoamericana de Ministros de Turismo, desarrollada en Asunción-Paraguay, junio 2011; el Informe del II Congreso Internacional de Ética y Turismo de la OMT, realizado en Ecuador, en septiembre de 2012, así como los videos de participación de los invitados expertos y los debates), la encuesta por cuestionario en internet y la aplicación de entrevistas a profundidad a expertos. En la estrategia metodológica se ha combinado la encuesta por cuestionario con una entrevista a profundidad semiestructurada con algunos expertos. Además, hemos contado con datos secundarios, que es información que han generado otros investigadores anteriormente (Palacios, 1999a).

La documentación disponible permitió identificar una serie de factores, que, en una segunda etapa, a través de encuestas por cuestionario electrónico fueron presentados a la opinión de expertos para identificar la relevancia de los factores expuestos en esta filosofía. Además, se validó el perfil de los expertos para ser considerados en los resultados del estudio. Dicha validación de los expertos se realizó en base a parámetros como la experiencia del individuo en el sector turismo, la evidencia de trabajos de investigación (ponencias en congresos, publicaciones o revistas 
sobre el sector) y ocupación actual ligada a la investigación o desenvolvimiento de actividades turísticas.

La encuesta por cuestionario es la técnica de investigación social por excelencia. El cuestionario debe responder a los objetivos de la encuesta, elabora un plan de preguntas y proceder a su redacción; y preparar la aplicación del cuestionario en sus aspectos logísticos (Palacios, 1999b). La encuesta es útil para describir algo y para contrastar hipótesis o modelos. (Alvira Martín, 2011). La principal utilidad es generar descripciones que expliquen el significado y variación de los elementos del contexto individual y grupal. Las preguntas del cuestionario y los resultados que generan son significativas, cuando están asociados con datos cualitativos obtenidos e integrados en un modelo teórico (Cubo et al., 2011a).

Finalmente, el estudio se complementó con una tercera etapa, mediante la aplicación de entrevistas a profundidad a expertos del sector turismo. La entrevista es una técnica cualitativa, en la que los investigadores establecen relaciones respetuosas con los entrevistados, incluyendo suficiente rapport como para que se establezca un intercambio de puntos de vista y suficiente tiempo y sinceridad, para que el entrevistado explore junto con el entrevistador el significado de los sucesos que tienen lugar en su mundo (Heyl, 2001). Rapport se entiende el clima agradable que debe generarse para facilitar la confianza y comunicación del entrevistado y el entrevistador. La entrevista es ante todo la interacción, una conversación entre investigador y entrevistado; cuyo conocimiento que se produce como consecuencia de esta conversación es fruto de una interacción, de un intercambio de puntos de vista (Kvale, 1996). Además, es importante señalar que se ha utilizado una entrevista semiestructurada, que combina la flexibilidad de las entrevistas no estructuradas con la direccionalidad de un instrumento cuyo objetivo es obtener datos cualitativos centrados en un tema concreto. Las cuestiones que orientan una entrevista semiestructurada son formuladas con antelación, las respuestas suelen ser abiertas, logrando mayor información (Cubo et al., 2011b).

Los resultados del estudio cualitativo sustentan e identifican los factores que fueron puestos a consideración de la opinión de los turistas que visitan Ecuador, en el caso específico del Distrito Metropolitano de Quito, capital ecuatoriana, punto de entrada con mayor afluencia por el turismo receptor.

\subsection{Decisiones muestrales}

En relación con la selección de la muestra según Palacios (1999) no siempre es posible tener una muestra idónea, que constituya una representación a escala de la población, bien porque no conocemos el tamaño real de la población o bien porque la muestra no es extraíble en las circunstancias reales. Regularmente no se pretende generalizar los resultados obtenidos en la muestra a una población; se identifica unos cuantos sujetos porque no se pretende necesariamente generalizar los resultados del estudio (Hernández et al., 2006b). En el estudio cualitativo, la aplicación de las encuestas a expertos consideró tres tipos de muestreo.

- No probabilístico simple, al aplicar un cuestionario a una población indiscriminada sin una muestra estadística, al no conocer el tamaño de la población. 
- Conveniencia sobre el número de sujetos de la muestra y con quienes mejor analicen e interpreten el fenómeno del "Turismo Consciente".

- Y bola de nieve, al valerse de las referencias e información de los sujetos expertos que fueron investigados.

\subsection{Recogida de datos}

En lo referente a los datos secundarios, la documentación disponible fue solicitada a los diferentes organismos tanto nacionales como internacionales; sobre lo cual se pudo acceder al libro publicado sobre el II Congreso Internacional de Ética y Turismo de la OMT; y los videos de las participaciones de las diferentes autoridades y expertos asistentes al evento.

La recogida de datos de la encuesta por cuestionario requirió de tres estudios piloto que garantizasen que la población objeto de estudio comprendía las cuestiones a ser investigadas. Se realizaron dos pruebas piloto en el mes de diciembre 2015 e inicios de 2016, a un grupo de 12 y 15 personas expertas en investigación de mercados y turismo, ubicadas en España y Ecuador. Del resultado de estas pruebas piloto, se logró tener un formulario final, que fue diseñado en idioma español e inglés para su trabajo de campo propiamente dicho.

El trabajo de campo se desarrolló del 18 de enero al 19 de febrero, a una base de datos de 334 expertos, de países tales como: Portugal, España, Brasil, Ecuador y otros países. Los expertos fueron validados, se adaptó la metodología aplicada por García \& Fernández (2008), estableciéndose las siguientes acciones: generación de un listado de posibles expertos, selección de expertos y validación de expertos.

Los parámetros para la validación y los criterios considerados fueron:

- Experiencia del individuo en el sector turismo:
- Baja, de 0 a 5 años
- Moderada, de 5 a 10 años
- Media, de 10 a 15 años
○ Alta, de 15 a 20 años, y
- Experto, más de 20 años.

- Evidencia del desarrollo de ponencias en congresos, investigaciones, publicaciones o revistas sobre el sector con o sin evidencias

- Ocupación actual ligada a la investigación o desenvolvimiento de actividades turísticas:
○ preponderante, investigación y docencia - doctorado afín
o importante, docencia - doctorado afín
- normal, actividades en el sector - master afín 
Tabla 1: Parámetros y Estadísticos de la Validación de Expertos del Estudio

\begin{tabular}{|c|c|c|c|c|c|c|c|c|}
\hline Parámetros & \multicolumn{2}{|c|}{$\begin{array}{l}\text { Valoración - tiempo } \\
\text { de experiencia en el } \\
\text { sector Turismo }\end{array}$} & \multicolumn{2}{|c|}{$\begin{array}{l}\text { Valoración - } \\
\text { experiencia obtenida } \\
\text { en actividades } \\
\text { profesionales }\end{array}$} & \multicolumn{2}{|c|}{$\begin{array}{l}\text { Valoración - } \\
\text { desarrollo de trabajos } \\
\text { de investigación }\end{array}$} & \multicolumn{2}{|c|}{$\begin{array}{c}\text { Coeficiente de } \\
\text { Competencia } \\
\text { Profesional (CCP) }\end{array}$} \\
\hline \multirow[t]{2}{*}{ Peso } & \multicolumn{2}{|c|}{$50 \%$} & \multicolumn{2}{|l|}{$30 \%$} & \multicolumn{2}{|c|}{$20 \%$} & \multirow[t]{2}{*}{ ALTO } & \multirow[t]{2}{*}{0,8 a 1} \\
\hline & \multicolumn{2}{|c|}{0,5} & \multicolumn{2}{|l|}{0,3} & \multicolumn{2}{|c|}{0,2} & & \\
\hline \multirow[t]{5}{*}{ Criterios } & Baja & 0,1 & & & & & \multirow[t]{2}{*}{ MEDIO } & \multirow{2}{*}{$\begin{array}{c}0,5 \mathrm{a}< \\
0,8\end{array}$} \\
\hline & Moderada & 0,2 & Preponderante & 0,3 & Con trabajos & 0,2 & & \\
\hline & Media & 0,3 & Importante & 0,2 & Sin trabajos & 0,1 & \multirow[t]{2}{*}{ BAJO } & \multirow[t]{2}{*}{$<0,5$} \\
\hline & Alta & 0,4 & Normal & 0,1 & & & & \\
\hline & Experto & 0,5 & & & & & & \\
\hline
\end{tabular}

\begin{tabular}{lrrrr}
\hline \multicolumn{1}{c}{ PARÁMETROS } & EXPERIENCIA & OCUPACIÓN & INVESTIGACIÓN & $\begin{array}{c}\text { COEFICIENTE DE } \\
\text { COMPETENCIA } \\
\text { PROFESIONAL }\end{array}$ \\
\hline $\mathbf{N}$ & & & \multicolumn{2}{c}{ PR descriptivos } \\
\hline Rango & 63 & 63 & 63 &, 60 \\
\hline Mínimo &, 40 &, 20 & 0,00 &, 40 \\
\hline Máximo &, 10 &, 10 &, 20 & 1,00 \\
\hline Media &, 50 &, 30 &, 20 &, 7032 \\
\hline &, 2746 &, 2286 &, 2000 &, 01852 \\
\hline Desviación estándar &, 01631 &, 00695 & 0,00000 &, 14698 \\
\hline
\end{tabular}

Dicha validación permitió establecer el Coeficiente de Competencia Profesional, que clasifica a los expertos en alta, media y baja. Se realizaron 63 encuestas, de cuya base, al ser validadas los parámetros con sus criterios, se consideró para el estudio un Coeficiente de Competencia Profesional alto y medio, dando un total de 60 encuestas validadas para el estudio (Tabla 1).

Las entrevistas a profundidad fueron siete acercamientos a expertos, con un perfil preponderante de alta experiencia dentro del sector turismo, y que expresaron un interés propio en el desarrollo de la investigación. Las entrevistas se realizaron entre el 04 al 18 de febrero, con una guía de entrevista a profundidad relacionada con los temas revisados en la encuesta por cuestionario electrónico.

\subsection{Análisis de los datos}

El análisis de datos tiene lugar durante e inmediatamente concluida la recogida de datos. En relación a la documentación disponible, se analizó los aspectos relevantes, con el fin de sustentar el diseño de la encuesta por cuestionario electrónico.

En la encuesta por cuestionario electrónico, se analizó principalmente a través de preguntas cerradas, aunque también con preguntas abiertas, los aspectos relacionados con los grupos de interés, dimensiones y variables del "Turismo Consciente". 
En las entrevistas a profundidad, se profundiza en los aspectos claves que se evidenciaron en la documentación disponible y las encuestas por cuestionario, que dan un valor agregado al concepto de la filosofía de "Turismo Consciente".

Finalmente se identificaron y contrastaron aspectos similares y diferenciadores en la triangulación de datos y métodos, obteniendo conclusiones relevantes para el caso de estudio del Distrito Metropolitano de Quito.

\section{RESULTADOS}

\subsection{Resultados de las encuestas por cuestionario electrónico a expertos}

Los principales resultados de la aplicación de las encuestas por cuestionario electrónico a expertos son:

\subsubsection{Perfil de los expertos encuestados}

Se trata de una persona con una experiencia media en el sector de 13 años, con un nivel de experiencia moderada entre 5 a 10 años y media entre 10 a 15 años mayormente, ocupados principalmente en tareas de docencia e investigación; originaros de Portugal, España, Brasil y Ecuador principalmente.

\subsubsection{Aspectos priorizados del "Turismo Consciente"}

El "Turismo Consciente", orienta sus esfuerzos en tres grandes grupos de interés, los seres humanos, las comunidades locales anfitrionas y las actividades empresariales.

Desde la óptica de los expertos, se les solicito que priorizaran cada uno de los aspectos libremente, dando como resultado que los seres humanos vean a los viajes principalmente como un crecimiento y enriquecimiento personal, una experiencia de vida transformadora, que busca la felicidad, para transformarla en una celebración de la vida, entre otros factores (Tabla 2).

Tabla 2: Estadísticos - Aspectos claves generales del "Turismo Consciente" - Seres Humanos

\begin{tabular}{|c|c|c|c|c|c|}
\hline & & $\begin{array}{c}\text { Una experiencia } \\
\text { vital } \\
\text { transformadora }\end{array}$ & $\begin{array}{l}\text { Induce al } \\
\text { crecimiento y } \\
\text { enriquecimiento } \\
\text { personal }\end{array}$ & $\begin{array}{c}\text { Se } \\
\text { transforma } \\
\text { en una } \\
\text { celebración } \\
\text { de la vida }\end{array}$ & $\begin{array}{l}\text { Una } \\
\text { búsqueda } \\
\text { de la } \\
\text { felicidad }\end{array}$ \\
\hline \multirow[t]{2}{*}{$\mathbf{N}$} & Válido & 60 & 60 & 60 & 60 \\
\hline & Perdidos & 0 & 0 & 0 & 0 \\
\hline \multicolumn{2}{|l|}{ Media } & 1,93 & 1,80 & 3,15 & 3,12 \\
\hline \multicolumn{2}{|c|}{ Error estándar de la media } & 123 & 118 & 118 & 119 \\
\hline \multicolumn{2}{|c|}{ Desviación estándar } & ,954 & 917 & 917 & ,922 \\
\hline \multicolumn{2}{|l|}{ Rango } & 3 & 3 & 3 & 3 \\
\hline \multicolumn{2}{|l|}{ Mínimo } & 1 & 1 & 1 & 1 \\
\hline \multicolumn{2}{|l|}{ Máximo } & 4 & 4 & 4 & 4 \\
\hline \multirow[t]{3}{*}{ Percentiles } & 25 & 1,00 & 1,00 & 3,00 & 3,00 \\
\hline & 50 & 2,00 & 2,00 & 3,00 & 3,00 \\
\hline & 75 & 2,75 & 2,00 & 4,00 & 4,00 \\
\hline
\end{tabular}


En la Figura 1, en una escala ordinal (en donde 4 es el más importante y 1 será menos importante), tenemos que el aspecto del crecimiento y enriquecimiento personal tiene un promedio ponderado de 3,20 .

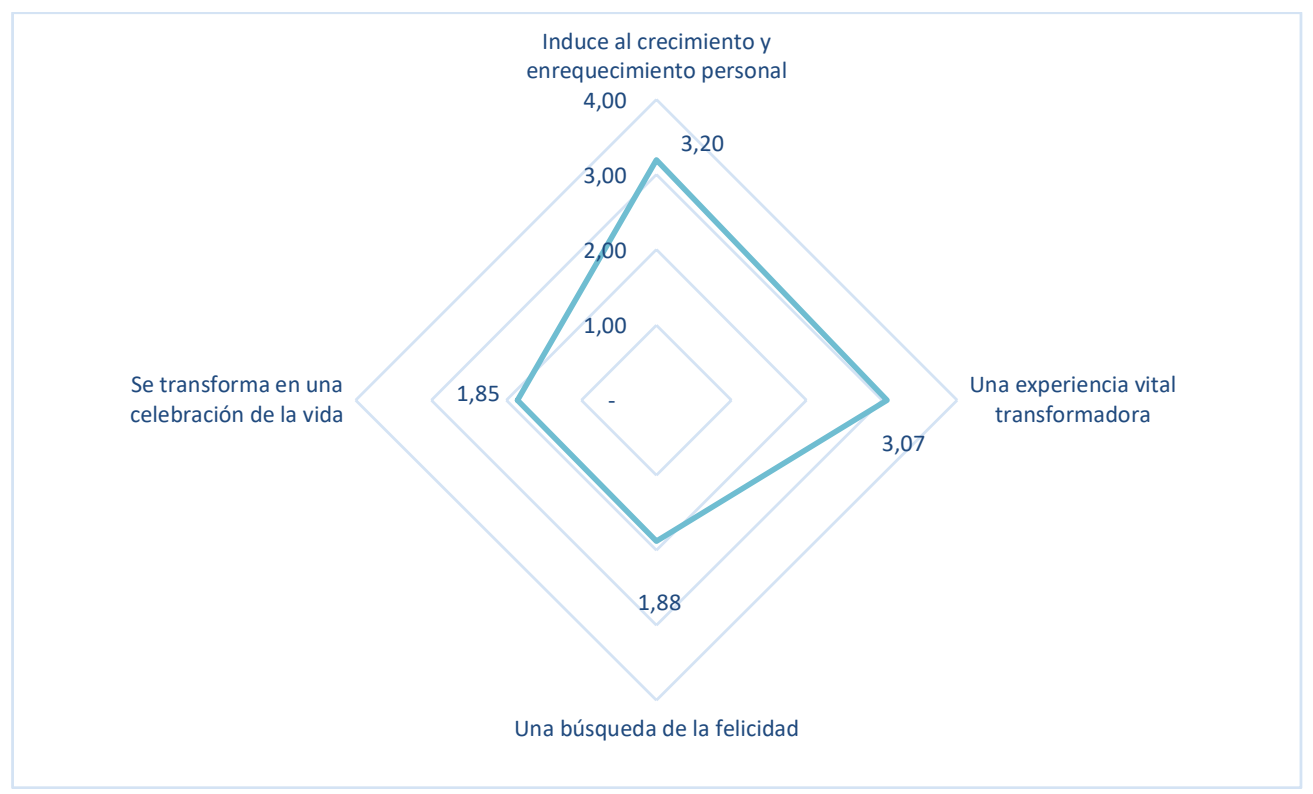

Figura 1: Promedio ponderado de los aspectos priorizados generales del "Turismo Consciente" - Seres Humanos

Los expertos de Alemania, Grecia, Portugal y Ecuador valoraron en mayor medida el aspecto de crecimiento y enriquecimiento personal; mientras que Alemania, Grecia, Eslovenia Ecuador, España y Brasil valoraron en menor medida el aspecto de transformación en una celebración de vida (Figura 2).

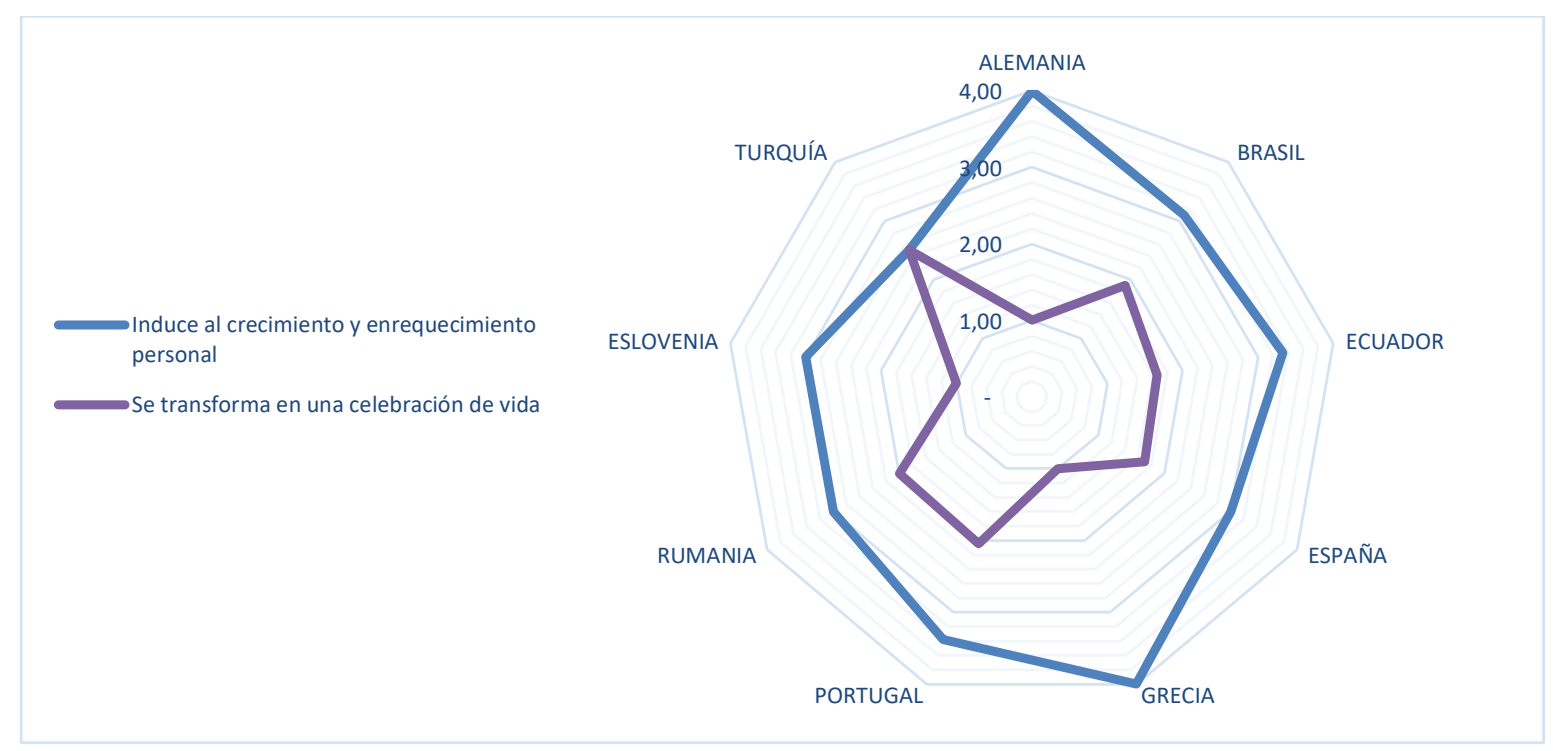

Figura 2: Aspectos priorizados por país de origen de los expertos sobre el "Turismo Consciente" - Seres Humanos

En relación a las comunidades locales anfitrionas, los expertos consideran prioritario que debe existir primero un pacto de convivencia entre las comunidades anfitrionas y los visitantes, 
seguido de un pacto de convivencia entre el patrimonio cultural y natural, el fomento del crecimiento beneficioso y distributivo a nivel social, la redefinición de los factores de consumo y medir la prosperidad en valores espirituales que materiales, entre otros aspectos, como se despliega en la Tabla 3.

Tabla 3: Estadísticos - Aspectos claves generales del "Turismo Consciente" - Comunidades locales anfitrionas

\begin{tabular}{|c|c|c|c|c|c|c|}
\hline \multicolumn{7}{|c|}{ Estadísticos } \\
\hline & & $\begin{array}{c}\text { Pacto de } \\
\text { convivencia } \\
\text { entre las } \\
\text { comunidades } \\
\text { anfitrionas y } \\
\text { los visitantes }\end{array}$ & $\begin{array}{l}\text { Pacto de } \\
\text { convivencia } \\
\text { entre el } \\
\text { patrimonio } \\
\text { cultural y } \\
\text { natural }\end{array}$ & $\begin{array}{l}\text { Redefinir } \\
\text { los } \\
\text { factores } \\
\text { de } \\
\text { consumo }\end{array}$ & $\begin{array}{l}\text { Medir más la } \\
\text { prosperidad } \\
\text { en valores } \\
\text { espirituales } \\
\text { que de } \\
\text { bienes } \\
\text { materiales }\end{array}$ & $\begin{array}{c}\text { Fomentar el } \\
\text { crecimiento } \\
\text { beneficioso y } \\
\text { distributivo a } \\
\text { nivel social }\end{array}$ \\
\hline \multirow[t]{2}{*}{$\mathbf{N}$} & Válido & 60 & 60 & 60 & 60 & 60 \\
\hline & Perdidos & 0 & 0 & 0 & 0 & 0 \\
\hline Media & & 1,85 & 2,68 & 3,73 & 3,92 & 2,82 \\
\hline Error estándar de la media & & 136 & 144 & 178 & 124 & , 188 \\
\hline Desviación estándar & & 1,055 & 1,112 & 1,376 & 962 & 1,455 \\
\hline Rango & & 4 & 4 & 4 & 4 & 4 \\
\hline Mínimo & & 1 & 1 & 1 & 1 & 1 \\
\hline Máximo & & 5 & 5 & 5 & 5 & 5 \\
\hline \multirow[t]{3}{*}{ Percentiles } & 25 & 1,00 & 2,00 & 3,00 & 3,00 & 1,25 \\
\hline & 50 & 2,00 & 3,00 & 4,00 & 4,00 & 3,00 \\
\hline & 75 & 2,00 & 3,00 & 5,00 & 5,00 & 4,00 \\
\hline
\end{tabular}

En la Figura 3, en una escala ordinal (en donde 5 es el más importante y 1 será menos importante), tenemos que el aspecto de pacto de convivencia entre las comunidades anfitrionas y los visitantes tiene un promedio de ponderación de 4,15.

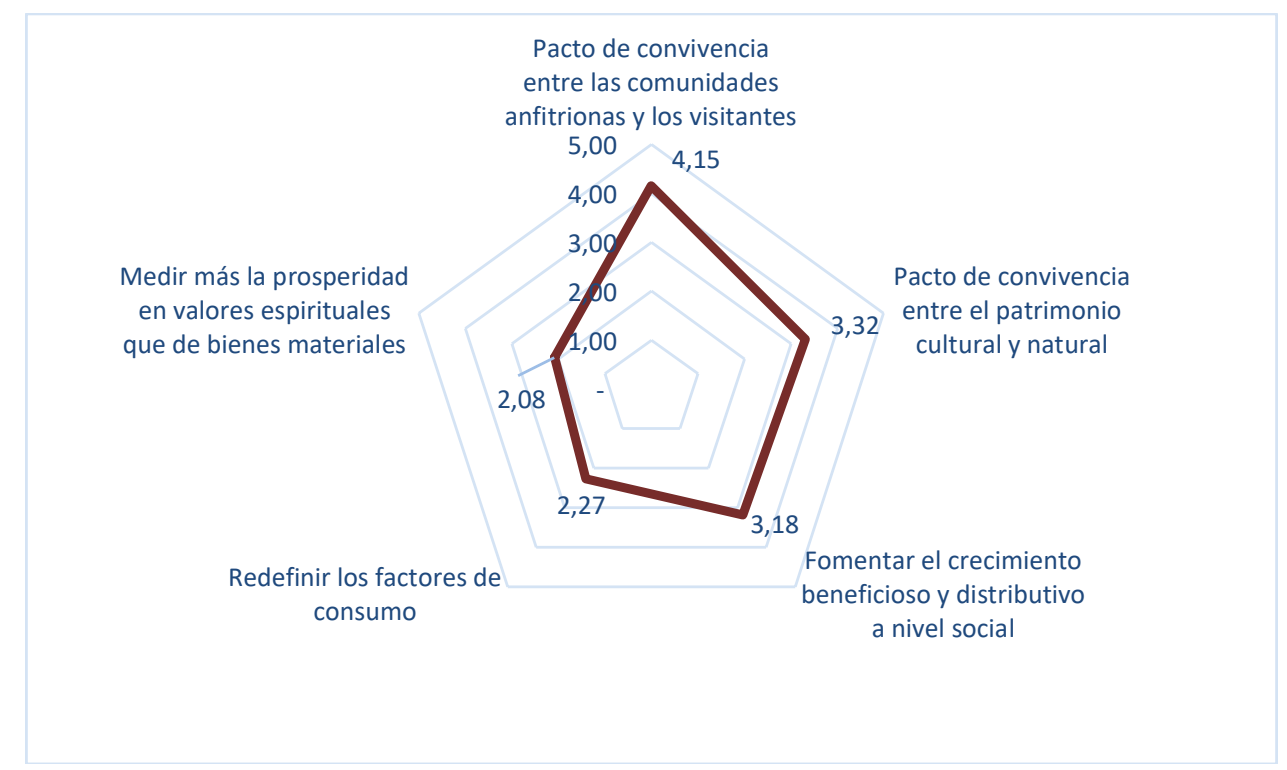

Figura 3: Promedio ponderado de los aspectos priorizados generales del "Turismo Consciente" 
Comunidades locales anfitrionas

Los expertos de Alemania, Turquía, Ecuador, Brasil y Portugal valoraron en mayor medida el aspecto de pacto de convivencia entre las comunidades anfitrionas y los visitantes; mientras que Rumania, Alemania y Turquía valoraron en menor medida el aspecto de fomentar el crecimiento beneficioso y distributivo a nivel social (Figura 4).

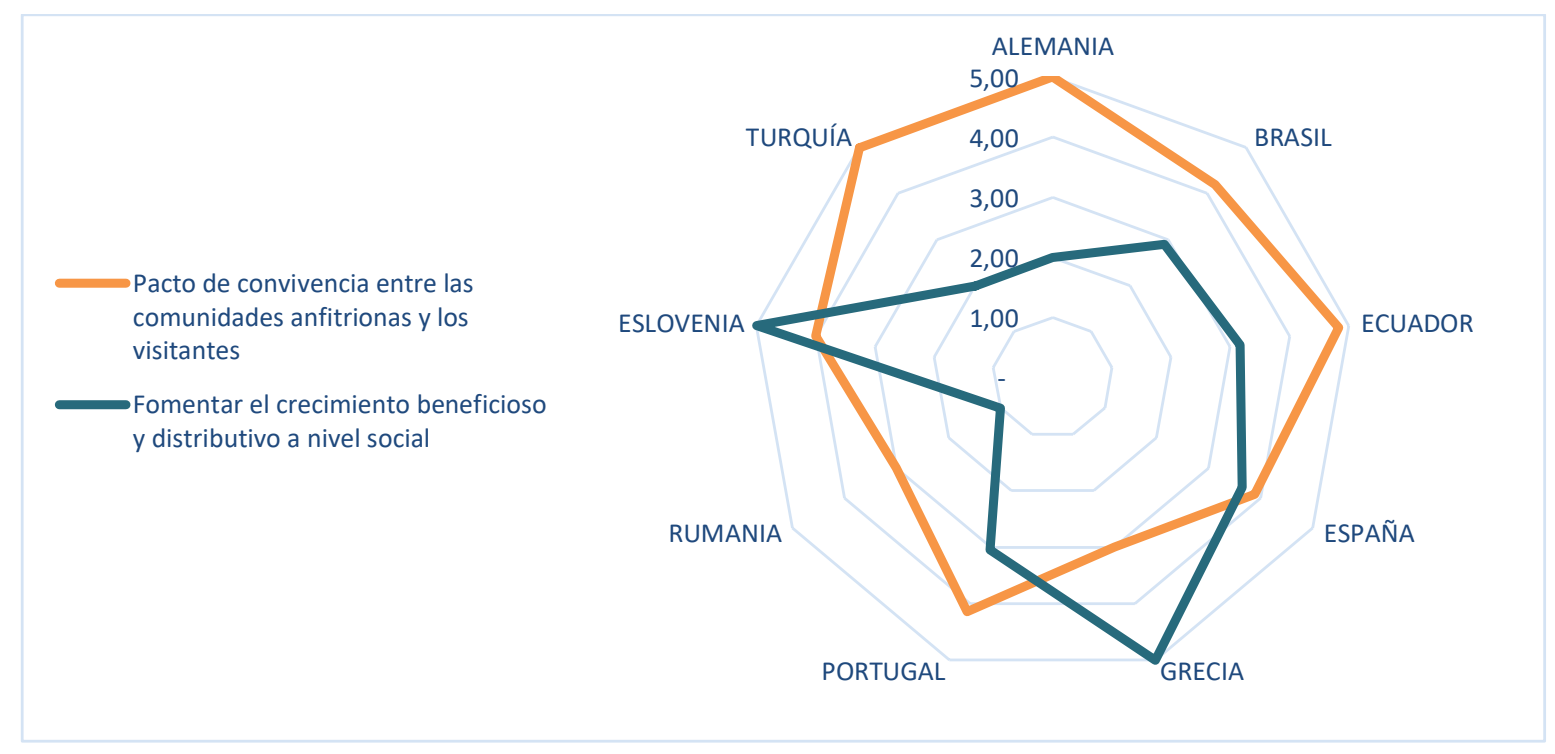

Figura 4: Aspectos priorizados por país de origen de los expertos sobre el "Turismo Consciente"

Comunidades anfitrionas locales

En referencia a las actividades empresariales los expertos consideran relevante primero el compromiso con la sociedad, seguido de un beneficio social del turismo, un beneficio económico y que contribuya a la mejora de la competitividad, entre otros factores (Tabla 4).

Tabla 4: Estadísticos - Aspectos claves generales del "Turismo Consciente" - Actividades empresariales

\begin{tabular}{|c|c|c|c|c|c|}
\hline \multicolumn{6}{|c|}{ Estadísticos } \\
\hline & & $\begin{array}{l}\text { Contribución a } \\
\text { la mejora de la } \\
\text { competitividad }\end{array}$ & $\begin{array}{l}\text { Compromiso } \\
\text { con la } \\
\text { sociedad }\end{array}$ & $\begin{array}{c}\text { Beneficio } \\
\text { económico } \\
\text { del } \\
\text { turismo }\end{array}$ & $\begin{array}{c}\text { Beneficio } \\
\text { social del } \\
\text { turismo }\end{array}$ \\
\hline \multirow[t]{2}{*}{$\mathbf{N}$} & Válido & 60 & 60 & 60 & 60 \\
\hline & Perdidos & 0 & 0 & 0 & 0 \\
\hline Media & & 3,38 & 1,60 & 2,97 & 2,05 \\
\hline Error estándar de la media & & 119 & 109 & 109 & 113 \\
\hline Desviación estándar & & 922 & ,848 & 843 & 872 \\
\hline Rango & & 3 & 3 & 3 & 3 \\
\hline Mínimo & & 1 & 1 & 1 & 1 \\
\hline Máximo & & 4 & 4 & 4 & 4 \\
\hline
\end{tabular}




\begin{tabular}{llllll}
\hline Percentiles & 25 & 3,00 & 1,00 & 2,00 & 1,00 \\
\cline { 2 - 6 } & 50 & 4,00 & 1,00 & 3,00 & 2,00 \\
\cline { 2 - 6 } & 75 & 4,00 & 2,00 & 4,00 & 2,00
\end{tabular}

En la Figura 5, en una escala ordinal (en donde 4 es el más importante y 1 será menos importante), tenemos que el aspecto de compromiso con la sociedad tiene una media de priorización de 3,40.

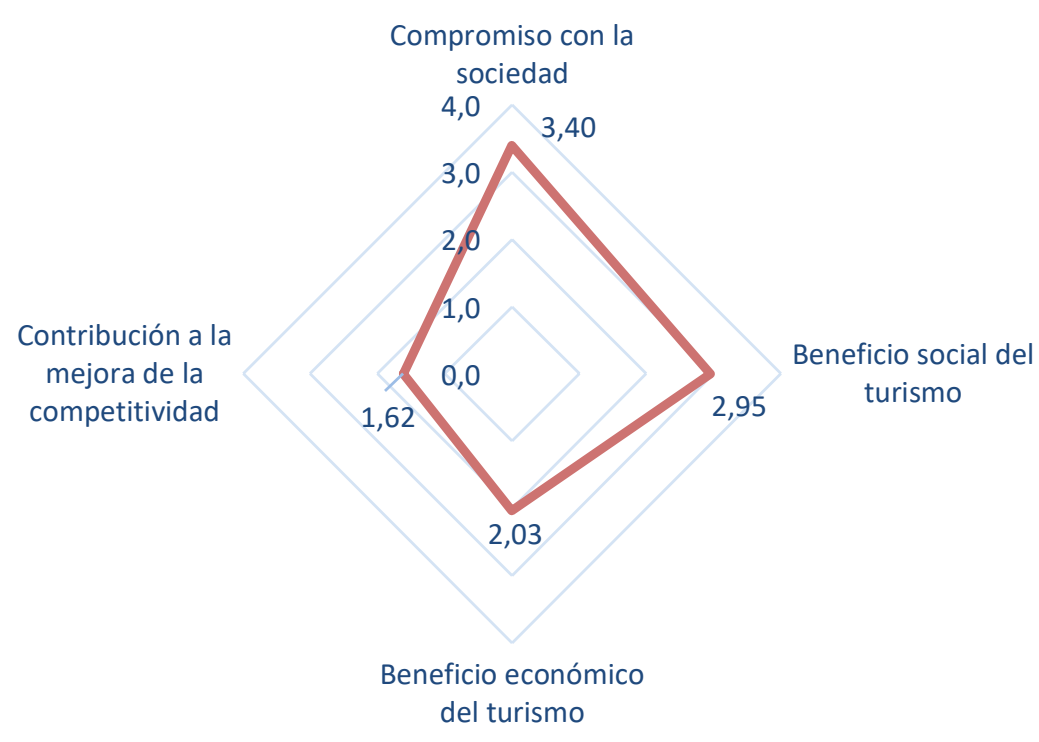

Figura 5: Promedio ponderado de los aspectos priorizados generales del "Turismo Consciente"

Actividades empresariales

Los expertos de Alemania, Grecia, Turquía, Brasil, España y Portugal valoraron en mayor medida el aspecto de compromiso con la sociedad; mientras que Alemania, Eslovenia, España, Brasil, Turquía y Portugal valoraron en menor medida el aspecto de contribución a la mejora dela competitividad (Figura 6).

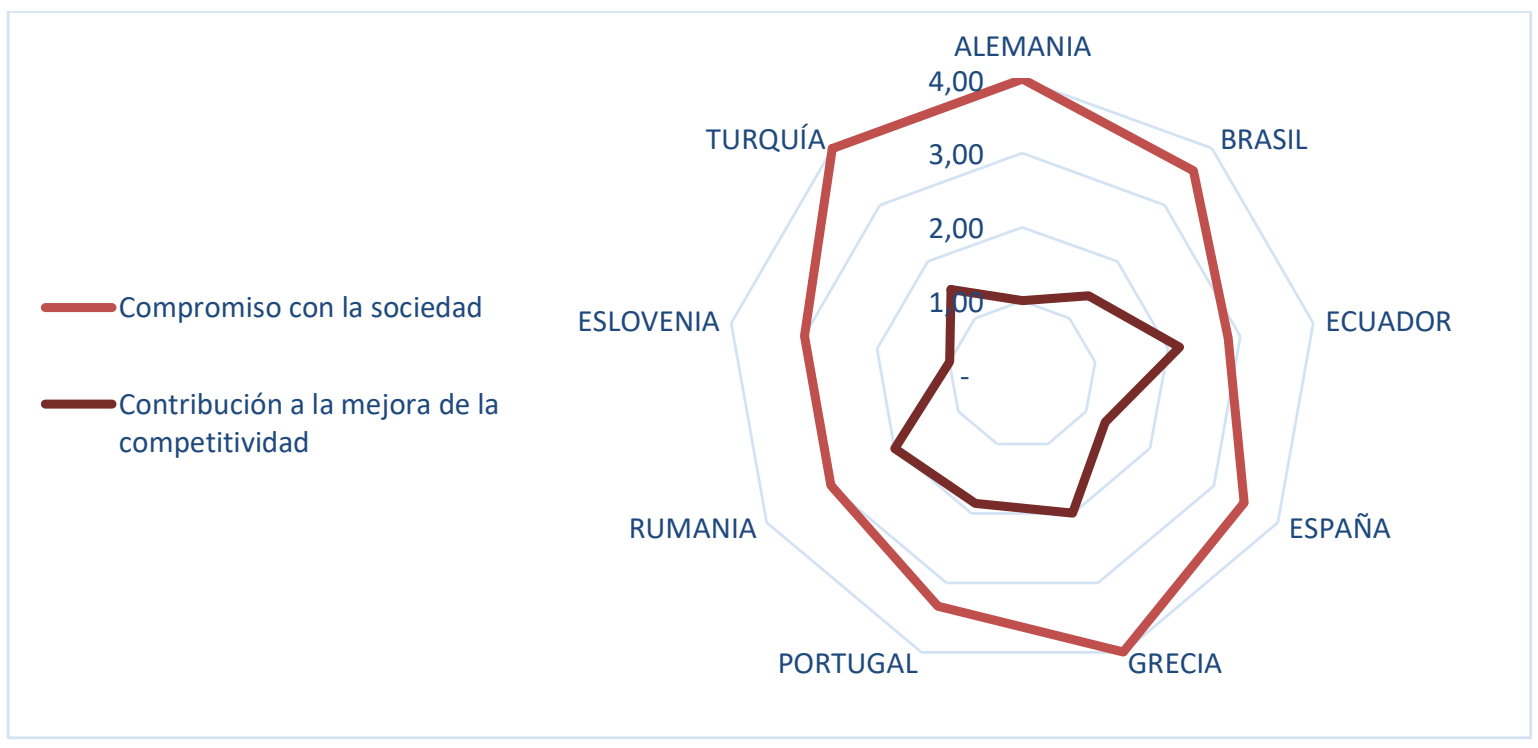


Figura 6: Aspectos priorizados por país de origen de los expertos sobre el "Turismo Consciente" - Actividades empresariales

El "Turismo Consciente" se sustenta en los principios de sostenibilidad y la ética. Los aspectos priorizados por los expertos, permite observar un grupo de factores que sobresalen sobre los demás, como son el respeto a los seres humanos, a las sociedades y la naturaleza, principalmente (Tabla 5).

Tabla 5: Estadísticos - Aspectos Éticos del "Turismo Consciente"

\begin{tabular}{|c|c|c|c|c|c|c|c|c|c|c|c|}
\hline & & $\mathbf{N}$ & Media & & Desviación & Rango & Mínimo & Máximo & & ercenti & \\
\hline & Válido & Perdidos & & la media & & & & & 25 & 50 & 75 \\
\hline $\begin{array}{l}\text { Respeto a los seres } \\
\text { humanos }\end{array}$ & 60 & 0 & 2,18 & 277 & 2,143 & 9 & 1 & 10 & 1,00 & 1,00 & 2,00 \\
\hline $\begin{array}{l}\text { Respeto a las } \\
\text { sociedades }\end{array}$ & 60 & 0 & 3,88 & ,278 & 2,156 & 8 & 1 & 9 & 2,00 & 3,00 & 6,00 \\
\hline $\begin{array}{l}\text { Respeto a la } \\
\text { naturaleza }\end{array}$ & 60 & 0 & 4,47 & 309 & 2,390 & 8 & 1 & 9 & 3,00 & 3,50 & 6,00 \\
\hline $\begin{array}{l}\text { Preocupación por } \\
\text { los grupos } \\
\text { vulnerables }\end{array}$ & 60 & 0 & 5,10 & ,293 & 2,268 & 9 & 1 & 10 & 4,00 & 5,00 & 6,00 \\
\hline Igualdad de genero & 60 & 0 & 5,82 & ,299 & 2,318 & 9 & 1 & 10 & 4,00 & 5,00 & 7,75 \\
\hline Incluyente & 60 & 0 & 5,55 & ,314 & 2,432 & 9 & 1 & 10 & 4,00 & 6,00 & 7,00 \\
\hline $\begin{array}{l}\text { Prevención de la } \\
\text { explotación sexual }\end{array}$ & 60 & 0 & 6,43 & 316 & 2,445 & 9 & 1 & 10 & 4,00 & 7,00 & 8,00 \\
\hline $\begin{array}{l}\text { Trabajo decente y } \\
\text { digno }\end{array}$ & 60 & 0 & 6,23 & ,302 & 2,339 & 9 & 1 & 10 & 5,00 & 6,50 & 8,00 \\
\hline $\begin{array}{l}\text { Responsabilidad } \\
\text { social corporativa }\end{array}$ & 60 & 0 & 6,83 & 353, & 2,738 & 9 & 1 & 10 & 5,00 & 8,00 & 9,00 \\
\hline $\begin{array}{l}\text { Contraponerse al } \\
\text { turismo de masas }\end{array}$ & 60 & 0 & 8,50 & 316 & 2,446 & 9 & 1 & 10 & 8,00 & 10,00 & 10,00 \\
\hline
\end{tabular}

En la Figura 7, en una escala ordinal (en donde 10 es el más importante y 1 será menos importante), tenemos que el aspecto de responsabilidad con los seres humanos tiene un promedio ponderado de 8,8 ; el respeto a las sociedades 7,1 ; el respeto a la naturaleza 6,5 entre los principales. 


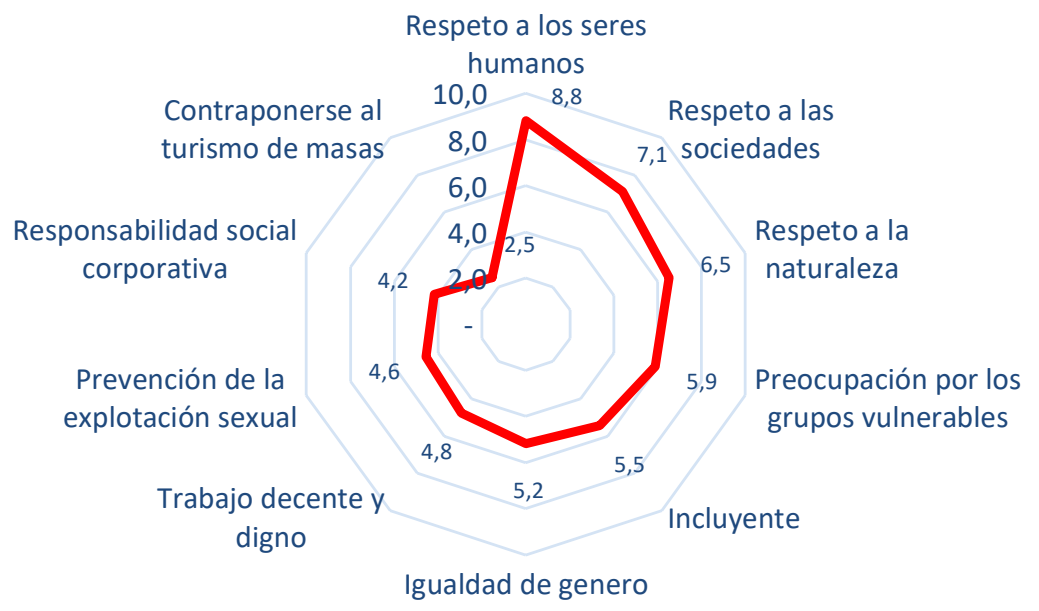

Figura 7: Promedio ponderado de los aspectos priorizados Éticos del "Turismo Consciente"

El aspecto más importante por origen de los expertos, es el respeto a los seres humanos, que está influenciado por el criterio de los expertos de Grecia, Eslovenia, España y Ecuador principalmente Figura 8.

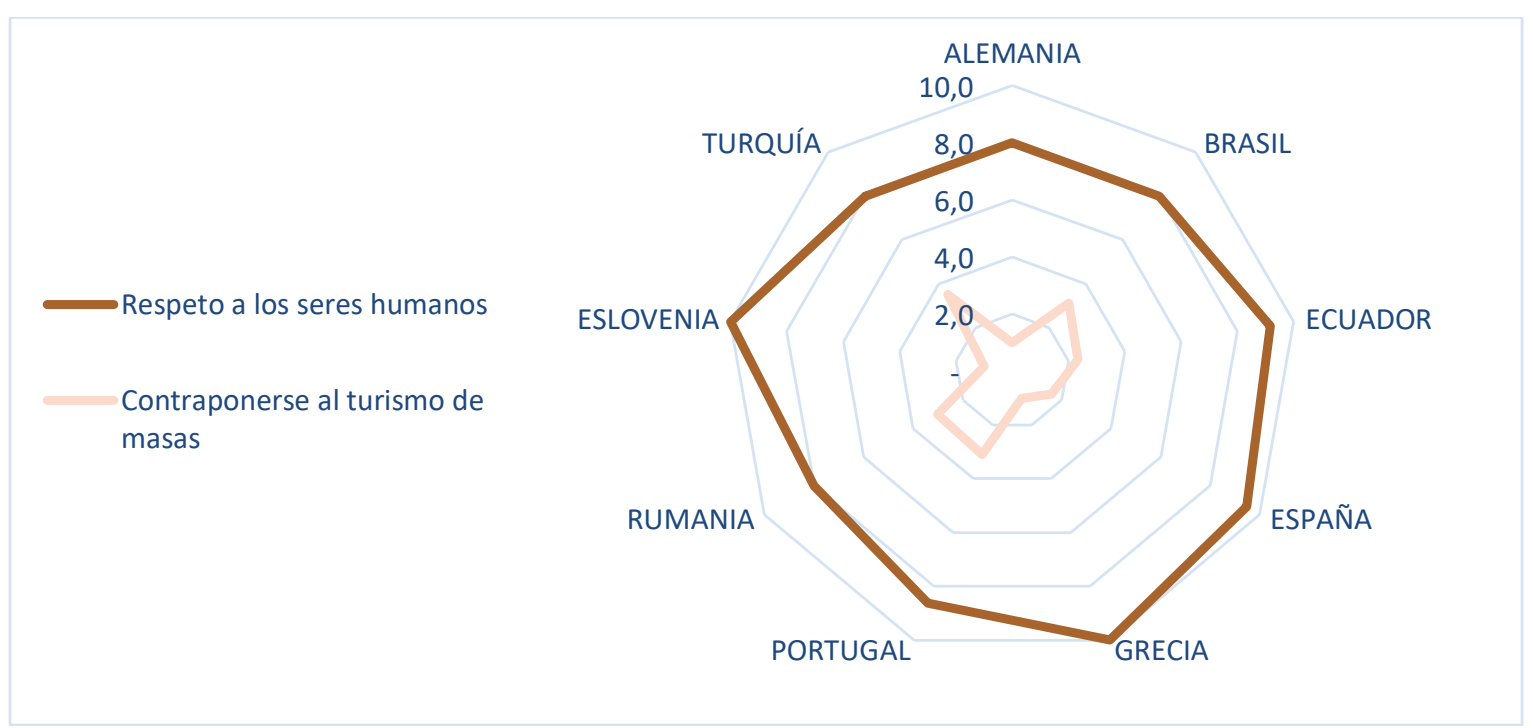

Figura 8: Aspectos Éticos priorizados por país de origen de los expertos sobre el "Turismo Consciente"

El "Turismo Consciente" se define como responsable, sostenible, ético e incluyente. La opinión de los expertos, en relación al plus diferenciador, consideraron que debería denominarse "Dimensión Ética" mayormente. 


\subsection{Entrevistas a profundidad con expertos de turismo}

Con las entrevistas en profundidad se pretendía, conocer la opinión de los expertos en relación con las tendencias actuales en turismo, así como las modalidades de turismo, la sostenibilidad y la profundización en los aspectos inherentes al "Turismo Consciente". Las entrevistas a profundidad fueron realizadas a siete expertos que formaron parte del grupo que cubrieron la encuesta por cuestionario electrónico, con un coeficiente de competencia profesional alta y media, que tuvieron interés sobre el nuevo concepto de "Turismo Consciente", bajo una guía de preguntas semiestructuradas. Los principales resultados fueron los que se presentan a continuación.

En relación con las tendenciales actuales del turismo existe una mayor concentración en brindar seguridad en el destino, mayor conciencia social, el avance de la tecnología de la información en beneficio del sector, así como la micro-segmentación. La demanda del turismo busca una oferta más personalizada, específica, adaptada a las necesidades y deseos de cada individuo; un turismo individualizado. El comportamiento del turista ha cambiado, se enfoca en el "darse cuenta" y en el "aquí y ahora", que tiene que ver con disfrutar de la experiencia turística, compartirlo y lograr bienestar al hacerlo.

En lo referente a las modalidades de turismo, el enfoque está en ofrecer alternativas al turismo senior, como el turismo experiencial (náutico, aventura, riesgo, etc.), el turismo para colectivos como LGTB, para singles, el turismo de frontera, el turismo termal o el turismo de naturaleza, entre otros.

Al hablar sobre sostenibilidad se considera que debe ser un condicionante inexcusable, una filosofía institucional y más global. Vivir de forma más consciente, debe ser uno de los pilares de la sostenibilidad dentro de esa consciencia en el mundo.

Al profundizar sobre la propuesta de la definición del "Turismo Consciente", se hace hincapié en la necesidad de una relación de igualdad entre los seres humanos, las sociedades, siempre en una posición de iguales. El "Turismo Consciente" parece más una filosofía que se puede aplicar a cualquier tipología turística, que se define de forma completa y precisa, que abarca a todas las partes dentro de esa experiencia. Este concepto debe tener un matiz social, no un bienestar individual, porque la ética en este sentido debe ser social, integral, holístico; lo consciente está por encima de lo sostenible.

En referencia a los grupos de interés del "Turismo Consciente" es necesario considerar las instituciones y administración pública, con el fin de interconectar y regular los mínimos establecidos por cada una de las partes. El objetivo de este grupo debe ser cohesionar los grupos de interés, coordinarlos, favorecer su cooperación y controlarlos.

Las dimensiones del turismo sostenible son transversales, en este sentido afecta a todos los sectores que están vinculados directa o indirectamente, no son estáticas. Por tanto, la cuarta dimensión debe ser considerada transversal.

El "Turismo Consciente" debe ser concebido como la evolución del propio turismo, que es demandado por las nuevas tendencias, con una visión a largo plazo y aunando esfuerzos para su aplicación en el sector. 
Los resultados del trabajo nos permiten definir el "Turismo Consciente" como una filosofía que es el resultado de la evolución del Turismo Sostenible, cuyo principal factor diferenciador es la dimensión ética, enfocada a cohesionar cuatro grandes grupos de interés, como son: todos los seres humanos involucrados en la experiencia turística; las comunidades anfitrionas locales como sociedad, en su conjunto, lugar y entorno; las actividades empresariales y las instituciones $u$ organismos públicos.

El "Turismo Consciente" se sustenta en que los viajes permiten a los seres humanos un crecimiento y enriquecimiento personal, que es una experiencia vital transformadora, que permite buscar la felicidad y celebrar la vida; todo esto enmarcado en los principios de igualdad y participación activa de todos los individuos.

En las comunidades anfitrionas locales se orienta en un pacto de convivencia entre anfitriones y visitantes, al igual que una convivencia entre lo cultural y lo natural, que genere crecimiento beneficioso y distribución social, redefiniendo los factores de consumo y midiendo la prosperidad en valores espirituales que materiales.

En las actividades empresariales busca el compromiso prioritario con la sociedad, que se evidencie en el beneficio social principalmente y económico, para la mejora de la competitividad.

Finalmente, las instituciones u organismos públicos deben ser el inter-conector entre los grupos de interés, para cohesionarlos con un fin común, regularlos y controlarlos.

El "Turismo Consciente" es una filosofía que evoluciona, dinámica, activa, que promueve la igualdad y la participación activa; es una experiencia de "dar y recibir"”".

\section{CONCLUSIONES}

El estudio desde la perspectiva de los expertos permite tener base de conocimiento sobre los aspectos relevantes del concepto de "Turismo Consciente" y el alcance de los grupos de interés y aspectos que permitan medir su aplicabilidad en el sector.

El "Turismo Consciente" es la evolución del Turismo Sostenible, es una filosofía que abarca las dimensiones de la sostenibilidad y la ética; que puede ser aplicado a todas las modalidades del turismo.

Para lograrlo, las dimensiones del "Turismo Consciente" están dadas por la sostenibilidad (económica, social, medioambiental) y la ética.

Los grupos de interés de la dimensión ética del "Turismo Consciente" se enfoca en los seres humanos, las comunidades anfitrionas locales, las actividades empresariales y las instituciones u organismos públicos.

La igualdad y la participación activa de los grupos de interés son aspectos relevantes del "Turismo Consciente", que genera una experiencia enriquecedora de "Dar y recibir".

Las dimensiones son transversales, es decir existe una relación entre todas las dimensiones y grupos de interés Figura 9. 


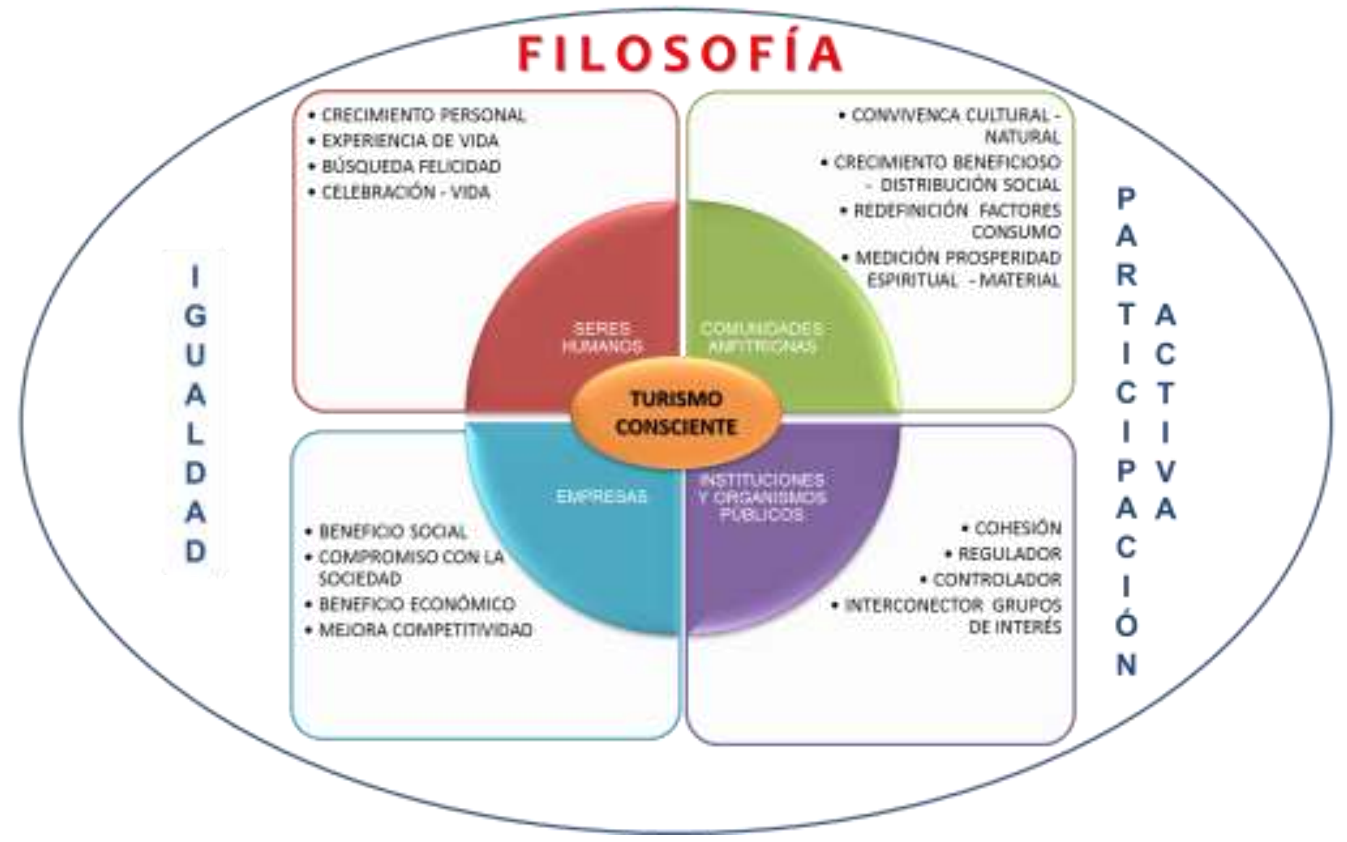

Figura 9: Delimitación conceptual del "Turismo Consciente”

Los resultados del estudio, permite establecer una amplia línea de investigación, enfocada en medir la viabilidad de su aplicación y medición en los grupos de interés, las dimensiones, constructos y variables en diferentes casos de estudios, que oriente la consecución de un modelo de validez general dentro del sector. Estudios que se orientan en conocer la percepción del turista receptor, turista interno, los stakeholders en relación con la definición, caracterización y grupos de interés que conforman el "Turismo Consciente".

Uno de esos trabajos, es el estudio que presenta la propuesta de un Modelo del "Turismo Consciente", mediante el caso de estudio de la Ciudad de Quito, capital del Ecuador, el cual ha sido considerado como uno de los destinos más populares de América Latina, siendo puerto de entrada principal del turismo receptor para Ecuador, que ofrece una amplia oferta turística (Castillo, E. et al., 2017).

El "Turismo Consciente" es una propuesta que puede ser potencializada, al tener resultados que permiten avizorar el desarrollo de la nueva filosofía. En futuros trabajos se planteará modelos correlacionales que redunden en beneficio de la línea de investigación.

\section{REFERENCIAS BIBLIOGRÁFICAS}

ALMEIDA-GARCíA, F., PELÁEZ-FERNÁNDEZ, M.A., BALBUENA-VÁZQUEZ, A. AND CORTÉS-MACÍAS, R. (2016), "Residents' perceptions of tourism development in Benalmádena (Spain)", Tourism Management, No. 54, pp. 259-274. https://doi.org/10.1016/i.tourman.2015.11.007

ALVIRA MARTíN, F. (2011). Cuadernos metodológicos. La encuesta: Una perspectiva general metodológica CIS.

ÁVILA, B. R., \& BARRADO, T. D. (2005). Nuevas tendencias en el desarrollo de destinos turísticos: Marcos conceptuales y operativos para su planificación y gestión. Cuadernos de Turismo, v.15, 
p.27-44.

CASTILLO, E., MARTINEZ, F., VAZQUEZ, E. (2017). "Turismo Consciente: Caso de Estudio de Quito desde la óptica del Turismo Receptor Internacional," Regional and Sectoral Economic Studies, Euro-American Association of Economic Development, vol. 17(1), pages 97-116.

CUBO, D. S., MARTÍN, M. B., \& RAMOS, S. J. L. (2011a). Técnicas e instrumentos de recogida de investigación. 2. El cuestionario: Recogida de datos estructurados. Métodos de investigación y análisis de datos en ciencias sociales y de la salud. p. 187. Madrid, España: Pirámide.

CUBO, D. S., MARTÍN, M. B., \& RAMOS, S. J. L. (2011b). Técnicas e instrumentos de recogida de investigación. 3. la entrevista. Métodos de investigación y análisis de datos en ciencias sociales y de la salud. p. 215, 216, 224. Madrid, España: Pirámide.

DENZIN, N. K. (1978). The research act. A theoretical introduction to sociological method. Nueva York: McGraw-Hill.

DENZIN, N. K., \& LINCOLN, Y. S. (1998). Strategies of qualitative inquiry. California, USA.: SAGE.

DENZIN, N. K., \& LINCOLN, Y. S. (2012). Manual de investigación cualitativa. El campo de la investigación cualitativa. [The Sage Handbook of Qualitative Research]. Barcelona, España.: Gedisa.

ERLANDSON, D. A., HARRIS, E. L., SKIPPER, B. L., \& ALLEN, S. D. (1993). Designing a naturalistic inquiry. Doing naturalistic inquiry. A guide to methods. p. 66. United States of America: SAGE.

EUROPA PRESS, 2. (2012). Economía FITUR. ecuador y la OMT apuestan por el "turismo consciente". Disponible en http://www.finanzas.com/noticias/economia/2012-01$\underline{18 / 639206}$ economia-fitur-ecuador-apuestan-turismo.html

FLICK, U. (2012). Introducción a la investigación cualitativa (3a. ed.). Madrid, España: Ediciones Morata, S. L.

GARCÍA, L., \& FERNÁNDEZ, S. J. (2008). Procedimiento de aplicación del trabajo creativo en grupo de expertos. Ingeniería Energética, v.29, n.2, p. 46-50.

GOODWIN, H. (2016), Responsible Tourism. Using tourism for sustainable development. Second Edition, Goodfellow Publishers Ltd., Oxford.

HERNÁNDEZ SAMPIERI, R., FERNÁNDEZ COLLADO, C., \& BAPTISTA LUCIO, P. (2006a). Metodología de la investigación (México [etc.]: McGraw Hill, cop. 2006 ed.)

HERNÁNDEZ SAMPIERI, R., FERNÁNDEZ COLLADO, C., \& BAPTISTA LUCIO, P. (2006a). 1. Similitudes y diferencias entre los enfoques cuantitativo y cualitativo. Metodología de la investigación $\mathrm{p}$. 13-14. México: McGraw Hill.

HERNÁNDEZ SAMPIERI, R., FERNÁNDEZ COLLADO, C., \& BAPTISTA LUCIO, P. (2006b). Definición del alcance de la investigación a realizar: Exploratoria, descriptiva, correlacional o explicativa. Metodología de la investigación p. 99-115. México: McGraw Hill. 
HEYL, B. (2001). In Handbook of ethnography (Ed.), Ethnographic interview. En P.M. Atkinson et al. Londres: Sage.

KVALE, S. (1996). In Thousand Oaks (Ed.), Interviews: An introduction to qualitative research interviewing. CA: Sage.

LEE, H.Y., BONN, M.A., REID, E.L. AND KIM, W.G. (2017), “Differences in tourist ethical judgment and responsible tourism intention: An ethical scenario approach", Tourism Management, Vol. 60, pp. 298-307. https://doi.org/10.1016/i.tourman.2016.12.003

NELSON, C., TREICHLER, P. A., \& GROSSBERG, L. (1992). Cultural studies. In En L. Grossberg, C. Nelson, \& P. A. Treichler (Eds.) (Ed.), Cultural studies. p. 1-16. New York: Routledge.

ORGANIZACIÓN MUNDIAL DEL TURISMO (2011). Regional Programme for the Americas. Turismo Consciente, una propuesta para amar la vida. Disponible en http://americas.unwto.org/news/2011-06-30/turismo-consciente-una-propuesta-para-amarla-vida

ORGANIZACIÓN MUNDIAL DEL TURISMO (2013). II Congreso Internacional de Ética y Turismo de la OMT. Quito (Ecuador). 11 y 12 septiembre 2012. Madrid, España.: OMT.

PALACIOS GÓMEZ, J. L. (1999a). Parte II. Las técnicas de investigación social. teoría y aplicaciones. 5. Recogida de datos secundarios. Técnicas de investigación social para servicios socioculturales p. 95-94. Granada: Centro de Estudios Municipales y de Cooperación Interprovincial, $\mathrm{CEMCl}$.

PALACIOS GÓMEZ, J. L. (1999b). Parte II. las técnicas de investigación social. teoría y aplicaciones. 6. La encuesta por cuestionario. Técnicas de investigación social para servicios socioculturales p. 109-160. Granada: Centro de Estudios Municipales y de Cooperación Interprovincial, CEMCI.

RED DE LA ORGANIZACIÓN MUNDIAL DE TURISMO (2011). Programa Regional para las Américas. Disponible en http://americas.unwto.org/es/node/29619

ROJAS SORIANO, R. (1991). Guía para realizar investigaciones sociales. p. 38, 156. México: Plaza y Valdés.

SU, L., HUANG, S. AND HUANG, J. (2018), "Effects of Destination Social Responsibility and Tourism Impacts on Residents' Support for Tourism and Perceived Quality Of Life", Journal of Hospitality \& Tourism Research, Vol. 7 No. 42, pp. 1039-1057. https://doi.org/10.1177/1096348016671395

PLAN NACIONAL DEL BUEN VIVIR 2013 - 2017 (2007). Objetivos Nacionales para el Buen Vivir

W.T.O. (2017), "Global Code of Ethics for Tourism. Ethics and Social Responsibility", available at: http://ethics.unwto.org/content/global-code-ethics-tourism 